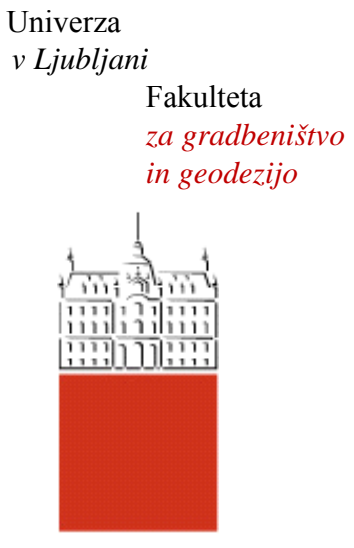

Jamova cesta 2

1000 Ljubljana, Slovenija

http://www3.fgg.uni-lj.si/

\section{DRUGG - Digitalni repozitorij UL FGG http://drugg.fgg.uni-lj.si/}

Ta članek je avtorjeva zadnja recenzirana različica, kot je bila sprejeta po opravljeni recenziji.

Prosimo, da se pri navajanju sklicujte na bibliografske podatke, kot je navedeno:
University
of Ljubljana

Faculty of

Civil and Geodetic

Engineering

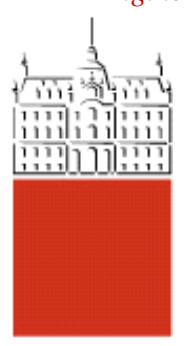

Jamova cesta 2

SI - 1000 Ljubljana, Slovenia

http://www3.fgg.uni-lj.si/en/

DRUGG - The Digital Repository http://drugg.fgg.uni-lj.si/

This version of the article is author's manuscript as accepted for publishing after the review process.

When citing, please refer to the publisher's bibliographic information as follows:

Schnabl, S., Planinc, I. 2010. The influence of boundary conditions and axial deformability on buckling behavior of two-layer composite columns with interlayer slip. Engineering Structures 32,10: 3103-3111 DOI: 10.1016/j.engstruct.2010.05.029. 


\title{
The influence of boundary conditions and axial deformability on buckling behavior of two-layer composite columns with interlayer slip
}

\author{
S. Schnabl* and I. Planinc \\ University of Ljubljana, Faculty of Civil and Geodetic Engineering, Jamova 2, \\ SI-1115 Ljubljana, Slovenia
}

\begin{abstract}
This paper presents a detailed analysis of the influence of boundary conditions and axial deformation on the critical buckling loads of the geometrically perfect elastic two-layer composite columns with inter-layer slip between the layers. An investigation is based on the extension of our preliminary analytical study of slipbuckling behavior of two-layer composite columns. It is proved that the boundary conditions of composite columns with interlayer slip are interrlated in longitudinal and transverse directions. The parametric analysis reveals that the influence of different longitudinal boundary conditions on critical buckling load is significant and can be up to $20 \%$, while, on the other hand, the influence of axial deformation is negligible.
\end{abstract}

Key words: boundary conditions, stability, buckling, analytical solutions, composite column, Reissner beam, slip, axial deformation, critical load, elasticity, layers. 


\section{Introduction}

In recent years, the applications of composite layered systems in automotive, aerospace, mechanical, and structural engineering industries have increased tremendously. The main advantages of composite systems over the conventional structures are their high strength-to-weight and stiffness-to-weight ratios. However, their mechanical behavior is considerably affected by the type of the connection between the constituents. For instance, in some widely used composite structures in civil engineering, such as nailed, glued or bolted layered wood systems, wood-concrete or steel-concrete systems, an absolutely stiff connection between the layers can hardly be realized in practice. As a result an interlayer slip between the layers develops, which can, if it has a sufficient magnitude, significantly affect the mechanical behaviour of the composite system.

Therefore, the inter-layer slip has to be taken into consideration in what is called partial interaction analysis of composite structures. Several researches have pursued the effect of partial composite action in the analysis of the abovementioned structures, and as a result, many published papers that take into account the inter-layer slip analytically or numerically are available in the literature. No attempt is made to discuss it here, but the interested reader is referred to, e.g., Adam et al. (1997), Dall'Asta and Zona (2004), Battini et al. (2009), Čas et al. (2004a), Čas et al. (2004b), Čas et al. (2007), Chen et al. (2007), Silva and Sousa (2009), Heuer and Adam (2000), Heuer (2004), Challamel (2009), Ranzi and Bradford (2007a), Ranzi and Zona (2007b), Ranzi

\footnotetext{
* Corresponding author. Tel.: +386 14768 615; Fax: +38614768629

E-mail address: sschnabl@fgg.uni-lj.si (S. Schnabl)
} 
(2008), Schnabl et al. (2006), Schnabl et al. (2007a), Schnabl et al. (2007b), and $\mathrm{Xu}$ and $\mathrm{Wu}(2007 \mathrm{~b})$.

Design of structures is often based on strength and stiffness considerations. However, a structure may become unstable long before strength and stiffness criteria are violated. Therefore, buckling is an important consideration in structural design, especially when the structure is slender and lightweight. Thus, it is of practical importance to obtain the analytical solutions for such problems.

There are relatively few analytical investigations of slip-buckling problem of composite columns with interlayer slip, and to date, only a few exact models have been developed. Rassam and Goodman (1970) derived a simplified solution of buckling behaviour of three layered wood columns with both equal and unequal layer thicknesses. Another analytical solution of buckling problem was derived by Girhammar and Gopu (1993). An extension and generalization of the latter theory is presented in Girhammar and Pan (2007). Recent papers by Xu and $\mathrm{Wu}(2007 \mathrm{a}), \mathrm{Xu}$ and $\mathrm{Wu}$ (2007b), and Xu and Wu (2007c) have presented an interesting approach to the solution of slip-buckling and vibration problem of composite beam-columns when shear deformation is taken into account. If shear deformation is neglected, the equations for buckling load obtained by $\mathrm{Xu}$ and $\mathrm{Wu}$ (2007a), Xu and Wu (2007b), and Xu and Wu (2007c) are the same as those presented by Girhammar and Pan (2007). The aforementioned solutions are based on what is called "second-order theory" and in Girhammar and Pan (2007) also on approximate buckling length coefficients. As it is well known, this theory neglects the influence of axial deformability on the critical buckling loads. Very recently, Kryžanowski et al. (2009) have proposed a slip-buckling analytical model in which the effect of axial deforma- 
bility on critical buckling forces is considered while, on the other hand, the effect of shear deformation is neglected. The comparison of the critical forces with those of Girhammar and Pan (2007) has shown a disagreement, which, unfortunately has not been explained in detail because only a preliminary parametric study was conducted at that time.

To complement the aforementioned studies, the main objective of the present paper is to clarify the reasons for disagreement between the results of Kryžanowski et al. (2009) and those of Girhammar and Pan (2007). For this purpose, equivalently as in Kryžanowski et al. (2009), a linearized stability theory is employed (Keller, 1970). Hence, critical buckling forces are determined from the solution of a linear eigenvalue problem, i.e., $\operatorname{det} \boldsymbol{K}=0$; see, e.g. (Planinc and Saje, 1999).

In the numerical examples critical buckling loads are compared to those of Girhammar and Pan (2007). Based on the derived results, the reasons for the disagreement between the models are clarified. Afterwards, a parametric study is conducted in order to illustrate how the critical buckling loads of geometrically perfect two-layer composite columns are affected by axial deformability and different arrangement of end supports. In particular, it is examined, how these effects are influenced by the inter-layer slip modulus, $K$, and column slenderness, $\lambda$. 


\section{Problem formulation}

Consider a geometrically perfect initially straight, planar, two-layer composite column of undeformed length $L$. Layers, as shown in Fig. 1, are marked by letters $a$ and $b$. The column is placed in the $(X, Z)$ plane of spatial Cartesian coordinate system with coordinates $(X, Y, Z)$ and unit base vectors $\boldsymbol{E}_{X}, \boldsymbol{E}_{Y}$ and $\boldsymbol{E}_{Z}=\boldsymbol{E}_{X} \times \boldsymbol{E}_{Y}$. The undeformed reference axis of the layered column is common to both layers and is defined as an intersection of the $(X, Z)$-plane and their contact plane. It is parametrized by the undeformed arc-length $x$. Local coordinate system $(x, y, z)$ is assumed to coincide initially with spatial coordinates, and then it follows the deformation of the column. Thus, $x^{a} \equiv x^{b} \equiv x \equiv X, y^{a} \equiv y^{b} \equiv y \equiv Y$, and $z^{a} \equiv z^{b} \equiv z \equiv Z$ in the undeformed configuration. The two-layer composite column is loaded longitudinally at the free end by an axial conservative compressive force, $P$, in such way that homogeneous stress-strain state of the column at its primary configuration is achieved. For further details an interested reader is referred to, e.g., Schnabl et al. (2007b) and Kryžanowski et al. (2009).

\subsection{Kinematic equations}

The deformed configurations of the reference axes of layers $a$ and $b$ are defined by vector-valued functions (see Fig. 1)

$$
\begin{aligned}
& \boldsymbol{R}_{0}^{a}=X^{a} \boldsymbol{E}_{X}+Y^{a} \boldsymbol{E}_{Y}+Z^{a} \boldsymbol{E}_{Z}=\left(x^{a}+u^{a}\right) \boldsymbol{E}_{X}+y^{a} \boldsymbol{E}_{Y}+w^{a} \boldsymbol{E}_{Z}, \\
& \boldsymbol{R}_{0}^{b}=X^{b} \boldsymbol{E}_{X}+Y^{b} \boldsymbol{E}_{Y}+Z^{b} \boldsymbol{E}_{Z}=\left(x^{b}+u^{b}\right) \boldsymbol{E}_{X}+y^{b} \boldsymbol{E}_{Y}+w^{b} \boldsymbol{E}_{Z},
\end{aligned}
$$

in which superscripts $a$ and $b$ indicate that quantities are related to layers $a$ and $b$, respectively. Functions $u^{a}$ and $w^{a}$ denote the components of the 

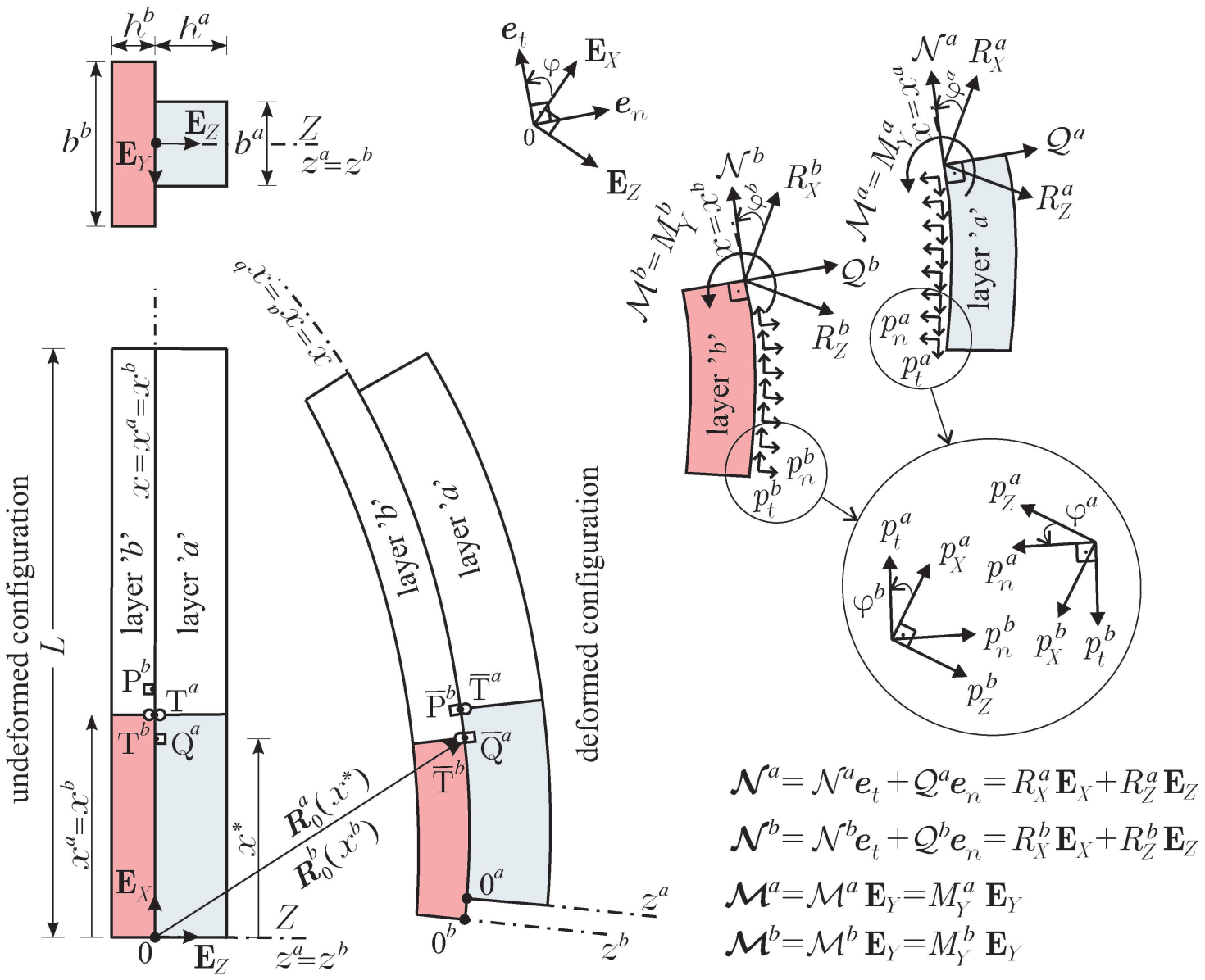

Figure 1. Undeformed and deformed configuration of the two-layer composite column and the generalized equilibrium internal forces and contact tractions expressed with respect to the fixed global and rotated local coordinate system.

displacement vector of layer $a$ at the reference axis with respect to the base vectors $\mathbf{E}_{X}$ and $\mathbf{E}_{Z}$. Similarly, functions $u^{b}$ and $w^{b}$ are related to layer $b$. The geometrical components $u^{a}, w^{a}, u^{b}$, and $w^{b}$ of the the vector-valued functions $\boldsymbol{R}_{0}^{a}$ and $\boldsymbol{R}_{0}^{b}$ are related to the deformation variables by the following equations, see, e.g. (Reissner, 1972):

layer $a$ :

$$
\begin{aligned}
& 1+u^{a \prime}-\left(1+\varepsilon^{a}\right) \cos \varphi^{a}=0, \\
& w^{a \prime}+\left(1+\varepsilon^{a}\right) \sin \varphi^{a}=0, \\
& \varphi^{a \prime}-\kappa^{a}=0,
\end{aligned}
$$


layer $b$ :

$$
\begin{aligned}
& 1+u^{b \prime}-\left(1+\varepsilon^{b}\right) \cos \varphi^{b}=0, \\
& w^{b \prime}+\left(1+\varepsilon^{b}\right) \sin \varphi^{b}=0, \\
& \varphi^{b \prime}-\kappa^{b}=0 .
\end{aligned}
$$

Here, the prime $\left({ }^{\prime}\right)$ denotes the derivative with respect to $x$. In Eqs. (2)(3), the deformation variables $\varepsilon^{a}$ and $\varepsilon^{b}$ are extensional strains; $\kappa^{a}$, and $\kappa^{b}$ are pseudocurvatures; while $\varphi^{a}$ and $\varphi^{b}$ are rotations of layers' reference axes (Vratanar and Saje, 1999).

\subsection{Equilibrium equations}

The composite column is subjected longitudinally to a conservative compressive force $P$ at the free end. In addition, each layer of the two-layer composite column is subjected to interlayer contact tractions, measured per unit of layer's undeformed length, which are defined by

$$
\begin{aligned}
& \boldsymbol{p}^{a}=p_{X}^{a} \boldsymbol{E}_{X}+p_{Z}^{a} \boldsymbol{E}_{Z}=\left(p_{t}^{a} \cos \varphi^{a}+p_{n}^{a} \sin \varphi^{a}\right) \boldsymbol{E}_{X}+\left(p_{n}^{a} \cos \varphi^{a}-p_{t}^{a} \cos \varphi^{a}\right) \boldsymbol{E}_{Z}, \\
& \boldsymbol{p}^{b}=p_{X}^{b} \boldsymbol{E}_{X}+p_{Z}^{b} \boldsymbol{E}_{Z}=\left(p_{t}^{b} \cos \varphi^{b}+p_{n}^{b} \sin \varphi^{b}\right) \boldsymbol{E}_{X}+\left(p_{n}^{b} \cos \varphi^{b}-p_{t}^{b} \cos \varphi^{b}\right) \boldsymbol{E}_{Z},
\end{aligned}
$$

where $p_{t}^{a}, p_{t}^{b}, p_{n}^{a}$, and $p_{n}^{b}$ are tangential and normal components of the interlayer contact tractions, see Fig. 1. Hence, the equilibrium equations of an individual layer are, see e.g. Reissner (1972) and Čas et al. (2007):

layer $a$ :

$$
\begin{aligned}
& R_{X}^{a \prime}+p_{X}^{a}=R_{X}^{a \prime}+p_{t}^{a} \cos \varphi^{a}+p_{n}^{a} \sin \varphi^{a}=0 \\
& R_{Z}^{a \prime}+p_{Z}^{a}=R_{Z}^{a \prime}-p_{t}^{a} \sin \varphi^{a}+p_{n}^{a} \cos \varphi^{a}=0 \\
& M_{Y}^{a \prime}-\left(1+\varepsilon^{a}\right) \mathcal{Q}^{a}=0
\end{aligned}
$$


layer $b$ :

$$
\begin{aligned}
& R_{X}^{b \prime}+p_{X}^{b}=R_{X}^{b \prime}+p_{t}^{b} \cos \varphi^{b}+p_{n}^{b} \sin \varphi^{b}=0 \\
& R_{Z}^{b \prime}+p_{Z}^{b}=R_{Z}^{b \prime}-p_{t}^{b} \sin \varphi^{b}+p_{n}^{b} \cos \varphi^{b}=0 \\
& M_{Y}^{b \prime}-\left(1+\varepsilon^{b}\right) \mathcal{Q}^{b}=0
\end{aligned}
$$

where

$$
\begin{aligned}
& \mathcal{N}^{a}=R_{X}^{a} \cos \varphi^{a}-R_{Z}^{a} \sin \varphi^{a}, \\
& \mathcal{Q}^{a}=R_{X}^{a} \sin \varphi^{a}+R_{Z}^{a} \cos \varphi^{a}, \\
& \mathcal{M}^{a}=M_{Y}^{a}, \\
& \mathcal{N}^{b}=R_{X}^{b} \cos \varphi^{b}-R_{Z}^{b} \sin \varphi^{b}, \\
& \mathcal{Q}^{b}=R_{X}^{b} \sin \varphi^{b}+R_{Z}^{b} \cos \varphi^{b}, \\
& \mathcal{M}^{b}=M_{Y}^{b} .
\end{aligned}
$$

$R_{X}^{a}, R_{Z}^{a}, R_{X}^{b}, R_{Z}^{b}, M_{Y}^{a}$, and $M_{Y}^{b}$ in (5)-(7) represent the generalized equilibrium internal forces of a cross-section of layers $a$ and $b$, respectively, with respect to the fixed coordinate basis. On the other hand, $\mathcal{N}^{a}, \mathcal{Q}^{a}, \mathcal{M}^{a}, \mathcal{N}^{b}, \mathcal{Q}^{b}$ and, $\mathcal{M}^{a}$ represent the equilibrium axial and shear internal forces and bending moments of the layers' cross-sections with respect to the rotated local coordinate system.

\subsection{Boundary conditions}

Kinematic equations, Eqs. (2-3), and equilibrium equations, Eqs. (5)-(6), constitute a system of 12 linear differential equations of the first order with constant coefficients for 12 unknown functions: $u^{a}, u^{b}, w^{a}, w^{b}, \varphi^{a}, \varphi^{b}, R_{X}^{a}, R_{X}^{b}$, $R_{Z}^{a}, R_{Z}^{b}, M_{Y}^{a}$, and $M_{Y}^{b}$. The associated natural and essential boundary conditions are: 
$x=0$ :

$$
\begin{aligned}
r_{1}^{0} R_{X}^{a}(0)+r_{2}^{0} u^{a}(0) & =-r_{1}^{0} P^{a}, \\
r_{3}^{0} R_{X}^{b}(0)+r_{4}^{0} u^{b}(0) & =-r_{3}^{0} P^{b}, \\
r_{5}^{0} R_{Z}^{a}(0)+r_{6}^{0} w^{a}(0) & =0, \\
r_{7}^{0} R_{Z}^{b}(0)+r_{8}^{0} w^{b}(0) & =0, \\
r_{9}^{0} M_{Y}^{a}(0)+r_{10}^{0} \varphi^{a}(0) & =-r_{9}^{0} \frac{h^{a}}{2} P^{a}, \\
r_{11}^{0} M_{Y}^{b}(0)+r_{12}^{0} \varphi^{b}(0) & =r_{11}^{0} \frac{h^{b}}{2} P^{b},
\end{aligned}
$$

$x=L:$

$$
\begin{aligned}
& r_{1}^{L} R_{X}^{a}(L)+r_{2}^{L} u^{a}(L)=-r_{1}^{L} P^{a}, \\
& r_{3}^{L} R_{X}^{b}(L)+r_{4}^{L} u^{b}(L)=-r_{3}^{L} P^{b}, \\
& r_{5}^{L} R_{Z}^{a}(L)+r_{6}^{L} w^{a}(L)=0, \\
& r_{7}^{L} R_{Z}^{b}(L)+r_{8}^{L} w^{b}(L)=0, \\
& r_{9}^{L} M_{Y}^{a}(L)+r_{10}^{L} \varphi^{a}(L)=-r_{9}^{L} \frac{h^{a}}{2} P^{a}, \\
& r_{11}^{L} M_{Y}^{b}(L)+r_{12}^{L} \varphi^{b}(L)=r_{11}^{L} \frac{h^{b}}{2} P^{b},
\end{aligned}
$$

where $r_{i} \in\{0,1\}$ are parameters that determine different combinations of boundary conditions of the two-layer composite column, where the superscripts " $0 "$ and " $L "$ of $s$ identify its value at $x=0$ and $x=L$, respectively. Besides, $P^{a}$ and $P^{b}$ represents an axial force that corresponds to the layer $a$ and $b$, respectively.

\subsection{Constitutive equations}

To relate the equilibrium internal forces $\mathcal{N}^{a}, \mathcal{Q}^{b}, \mathcal{N}^{a}$, and $\mathcal{Q}^{b}$ and equilibrium internal moments $\mathcal{M}^{a}$ and $\mathcal{M}^{b}$ to a material model, the following set of equations which assure the balance of equilibrium and constitutive cross-sectional 
forces and bending moments of the composite column are introduced. Due to the assumption that the transverse shear deformations are neglected, the well known constitutive equations of linear elastic two-layer composite columns are

$$
\begin{aligned}
& \mathcal{N}^{a}-\mathcal{N}_{C}^{a}\left(x, \varepsilon^{a}, \kappa^{a}\right)=\mathcal{N}^{a}-C_{11}^{a} \varepsilon^{a}-C_{12}^{a} \kappa^{a}=0, \\
& \mathcal{M}^{a}-\mathcal{M}_{C}^{a}\left(x, \varepsilon^{a}, \kappa^{a}\right)=\mathcal{M}^{a}-C_{21}^{a} \varepsilon^{a}-C_{22}^{a} \kappa^{a}=0, \\
& \mathcal{N}^{b}-\mathcal{N}_{C}^{b}\left(x, \varepsilon^{b}, \kappa^{b}\right)=\mathcal{N}^{b}-C_{11}^{b} \varepsilon^{b}-C_{12}^{b} \kappa^{b}=0, \\
& \mathcal{M}^{b}-\mathcal{M}_{C}^{b}\left(x, \varepsilon^{b}, \kappa^{b}\right)=\mathcal{M}^{b}-C_{21}^{b} \varepsilon^{b}-C_{22}^{b} \kappa^{b}=0,
\end{aligned}
$$

where, $\mathcal{N}_{C}^{a}, \mathcal{M}_{C}^{b}, \mathcal{N}_{C}^{b}$, and $\mathcal{M}_{C}^{b}$ are constitutive cross-sectional forces dependent only on deformation variables $\varepsilon^{a}, \kappa^{a}, \varepsilon^{b}$, and $\kappa^{b}$. Material and geometric constants are marked by $C_{11}^{a}, C_{12}^{a}, \ldots, C_{22}^{b}$; e.g., $C_{11}^{a}=E^{a} A^{a}$, where $A^{a}$ and $E^{a}$ denote the cross-sectional area and the elastic modulus of layer $a$, respectively; $C_{12}^{a}=E^{a} S^{a}$ and $C_{22}^{a}=E^{a} I^{a}$, where $S^{a}$ and $I^{a}$ denote the static moment and moment of inertia of layer $a$ with respect to the reference axis of the composite column, respectively; and so forth, see e.g. Kryžanowski et al. (2008) and Kryžanowski et al. (2009).

Furthermore, a constitutive law of the interlayer contact still has to be introduced. Herein, a linear constitutive law of bond slip between the layers is employed:

$$
p_{t}^{a}=K \Delta
$$

in which $K$ denotes a slip modulus at the interlayer surface and $\Delta$ denotes an interlayer slip. 


\subsection{Constraining equations}

In the two-layer composite column layer $b$ is constrained to follow the deformation of layer $a$ and vice versa. Since the layers can slip along each other but their transverse separation (uplift) or penetration is not allowed, the aforementioned fact can be expressed by a kinematic-constraint requirement as follows

$$
\boldsymbol{R}_{0}^{b}\left(T^{b}\right)=\boldsymbol{R}_{0}^{a}\left(Q^{a}\right)
$$

or, written differently

$$
\boldsymbol{R}_{0}^{b}(x)=\boldsymbol{R}_{0}^{a}\left(x^{*}\right)
$$

where $x$ and $x^{*}$ are coordinates of two distinct particles $T^{b}$ and $Q^{a}$ of layers $b$ and $a$ in the undeformed configuration which are in the deformed configuration in contact, see Fig. 1. Eqs. (12)-(13), when written in a componential form read

$$
\begin{aligned}
x+u^{b}(x) & =x^{*}+u^{a}\left(x^{*}\right), \\
w^{b}(x) & =w^{a}\left(x^{*}\right) .
\end{aligned}
$$

As a result of (14), a direct relation between the differentials of material coordinates $x$ and $x^{*}$ is easily defined as

$$
\frac{\mathrm{d} x^{*}}{\mathrm{~d} x}=\frac{\left(1+\varepsilon^{b}(x)\right) \cos \varphi^{b}(x)}{\left(1+\varepsilon^{a}\left(x^{*}\right)\right) \cos \varphi^{b}\left(x^{*}\right)} .
$$

Using (15), and taking into account the fact that the rotations of layers are identical (see, Kryžanowski et al. (2009))

$$
\varphi^{a}\left(x^{*}\right)=\varphi^{b}(x)
$$

it can be shown that the layers' pseudocurvatures are constrained to each 
other by

$$
\kappa^{a}\left(x^{*}\right) \frac{1+\varepsilon^{b}(x)}{1+\varepsilon^{a}\left(x^{*}\right)}=\kappa^{b}(x) .
$$

The slip that occurs between layers $a$ and $b$ is denoted by $\Delta$, (Čas et al., 2004a)

$$
\Delta^{\prime}(x)=\varepsilon^{a}(x)-\varepsilon^{b}(x) .
$$

Besides the above presented kinematic-constraint requirement (12), a stressconstraint requirement is determined from the third Newton's law, which ensures an equilibrium of the interlayer contact tractions of the particles in contact. This requirement is expressed in the vector-valued function form as

$$
\boldsymbol{p}^{a}(x)+\boldsymbol{p}^{b}(x)=\mathbf{0},
$$

and, by substituting (4) into (19), in componential form as

$$
\begin{aligned}
& p_{X}^{a}+p_{X}^{b}=p_{t}^{a} \cos \varphi^{a}+p_{n}^{a} \sin \varphi^{a}+p_{t}^{b} \cos \varphi^{b}+p_{n}^{b} \sin \varphi^{b}=0, \\
& p_{Z}^{a}+p_{Z}^{b}=-p_{t}^{a} \sin \varphi^{a}+p_{n}^{a} \cos \varphi^{a}-p_{t}^{b} \sin \varphi^{b}+p_{n}^{b} \cos \varphi^{b}=0 .
\end{aligned}
$$

Therefore, Eqs. (2)-(3), (5)-(11), (14), (18), and (19)-(20) compose a complete set of non-linear governing equations of a two-layer composite column, which consists of 32 equations for 32 unknown functions: $u^{a}, u^{b}, w^{a}, w^{b}, \varphi^{a}, \varphi^{b}, \varepsilon^{a}, \varepsilon^{b}, \kappa^{a}$, $\kappa^{b}, R_{X}^{a}, R_{X}^{b}, R_{Z}^{a}, R_{Z}^{b}, M_{Y}^{a}, M_{Y}^{b}, \mathcal{N}^{a}, \mathcal{N}^{b}, \mathcal{Q}^{a}, \mathcal{Q}^{b}, \mathcal{M}^{a}, \mathcal{M}^{b}, p_{X}^{a}, p_{X}^{b}, p_{Z}^{a}, p_{Z}^{b}, p_{t}^{a}, p_{t}^{b}, p_{n}^{a}$, $p_{n}^{b}, \Delta$, and, $x^{*}$. 


\section{Buckling analysis}

\subsection{Linearized stability equations}

The linearized stability equations for the determination of the critical load of composite columns, at the bifurcation point, can be derived by the application of the linearized theory of stability or linear theory of stability. It is based on the ascertainment that the critical bifurcation points of the non-linear system coincide with the critical points of the corresponding linearized system (Keller, 1970). The application of the linearized stability theory, regarding the existence and uniqueness of the solution of Reissner's elastica, is given by Flajs et al. (2003).

The abovementioned linearized theory of stability is founded upon the variation of a functional $\mathcal{F}$, here made in the sense of the continuous linear Gateaux operator or directional derivative, defined as follows (Hartmann, 1985)

$$
\delta \mathcal{F}(\boldsymbol{x}, \delta \boldsymbol{x})=\lim _{\alpha \rightarrow 0} \frac{\mathcal{F}(\boldsymbol{x}+\alpha \delta \boldsymbol{x})-\mathcal{F}(\boldsymbol{x})}{\alpha}=\left.\frac{\mathrm{d}}{\mathrm{d} \alpha}\right|_{\alpha=0} \mathcal{F}(\boldsymbol{x}+\alpha \delta \boldsymbol{x}),
$$

where $\boldsymbol{x}$ and $\delta \boldsymbol{x}$ represent the generalized displacement field and its increment, respectively, and $\alpha$ is an arbitrary small scalar parameter. Accordingly, it is convenient for Eqs. (2)-(3), (5)-(11), (14), (18), and (19)-(20) to be rewritten in compact form as $\mathcal{F}=\left\{\mathcal{F}_{1}, \mathcal{F}_{1}, \ldots, \mathcal{F}_{32}\right\}^{T}$, and their arguments as $\boldsymbol{x}=\left\{u^{a}, u^{b}, w^{a}, w^{b}, \ldots, p_{n}^{a}, p_{n}^{b}, \Delta, x^{*}\right\}^{T}$.

In order to apply linearized equations to the two-layer composite column buckling problem, these equations have to be evaluated at the primary configuration of the column, which is an arbitrary deformed configuration in which the 
composite column remains straight. The primary configuration is then defined as follows

$$
\begin{aligned}
& \varepsilon^{a}=\varepsilon^{b}=-\frac{1}{C_{11}^{a}+C_{11}^{b}} P, \\
& \kappa^{a}=\kappa^{b}=0, \\
& u^{a}=u^{b}=u^{a}(0)-\frac{x}{C_{11}^{a}+C_{11}^{b}} P \\
& w^{a}=w^{b}=0, \\
& \varphi^{a}=\varphi^{b}=0, \\
& x^{*}=x, \\
& \Delta=0, \\
& R_{X}^{a}=\mathcal{N}^{a}=-\frac{C_{11}^{a}}{C_{11}^{a}+C_{11}^{b}} P, \\
& R_{X}^{b}=\mathcal{N}^{b}=-\frac{C_{11}^{b}}{C_{11}^{a}+C_{11}^{b}} P \\
& R_{Z}^{a}=\mathcal{Q}^{a}=0, \\
& R_{Z}^{b}=\mathcal{Q}^{b}=0, \\
& M_{Y}^{a}=\mathcal{M}^{a}=-\frac{C_{21}^{a}}{C_{11}^{a}+C_{11}^{b}} P, \\
& M_{Y}^{b}=\mathcal{M}^{b}=-\frac{C_{21}^{b}}{C_{11}^{a}+C_{11}^{b}} P, \\
& p_{X}^{a}=p_{t}^{a}=0, \\
& p_{Z}^{b}=p_{t}^{b}=0, \\
& p_{n}^{a}=0, \\
& p_{n}^{b}=0 . \\
& p^{a}=0,
\end{aligned}
$$

As a result of linearization of Eqs. (2)-(3), (5)-(11), (14), (18), and (19)-(20), the linearized uncoupled equations of the two-layer composite column, when written at the primary configuration (22), are: 


$$
\begin{aligned}
& \delta \mathcal{F}_{1}=\delta u^{a \prime}-\delta \varepsilon^{a}=0, \\
& \delta \mathcal{F}_{2}=\delta u^{b \prime}-\delta \varepsilon^{b}=0, \\
& \delta \mathcal{F}_{3}=\delta w^{\prime}+(1+\varepsilon) \delta \varphi=0, \\
& \delta \mathcal{F}_{4}=\delta \varphi^{\prime}-\delta \kappa=0, \\
& \delta \mathcal{F}_{5}=\delta R_{X}^{a \prime}-\delta p_{t}=0, \\
& \delta \mathcal{F}_{6}=\delta R_{X}^{b \prime}+\delta p_{t}=0, \\
& \delta \mathcal{F}_{7}=\delta R_{Z}^{\prime}=0, \\
& \delta \mathcal{F}_{8}=\delta M_{Y}^{\prime}+R_{X} \delta w^{\prime}-(1+\varepsilon) \delta R_{Z}=0, \\
& \delta \mathcal{F}_{9}=\delta R_{X}^{a}-C_{11}^{a} \delta \varepsilon^{a}-C_{12}^{a} \delta \kappa=0, \\
& \delta \mathcal{F}_{10}=\delta R_{X}^{b}-C_{11}^{b} \delta \varepsilon^{b}-C_{12}^{b} \delta \kappa=0, \\
& \delta \mathcal{F}_{11}=\delta M_{Y}-C_{21}^{a} \delta \varepsilon^{a}-C_{21}^{b} \delta \varepsilon^{b}-\left(C_{22}^{a}+C_{22}^{b}\right) \delta \kappa=0, \\
& \delta \mathcal{F}_{12}=\delta \Delta-\delta u^{a}+\delta u^{b}=0, \\
& \delta \mathcal{F}_{13}=\delta p_{t}-K \delta \Delta=0, \\
& \delta \mathcal{F}_{14}=\delta x^{*}+\delta u^{a}-\delta u^{b}=0,
\end{aligned}
$$

where

$$
\begin{aligned}
& \varepsilon=-\frac{P}{C_{11}^{a}+C_{11}^{b}}, \\
& \delta w=\delta w^{a}=\delta w^{b}, \\
& \delta \varphi=\delta \varphi^{a}=\delta \varphi^{b}, \\
& \delta \kappa=\delta \kappa^{a}=\delta \kappa^{b}, \\
& R_{X}=-P \\
& \delta R_{Z}=\delta R_{Z}^{a}+\delta R_{Z}^{b}, \\
& \delta M_{Y}=\delta M_{Y}^{a}+\delta M_{Y}^{b}, \\
& \delta p_{t}=\delta p_{t}^{a}=-\delta p_{t}^{b} .
\end{aligned}
$$


Eqs. (23) constitute a system of 14 linear algebraic-differential equations of the first order with constant coefficients for 14 unknown functions: $\delta u^{a}, \delta u^{b}$, $\delta w, \delta \varphi, \delta \varepsilon^{a}, \delta \varepsilon^{b}, \delta \kappa, \delta R_{X}^{a}, \delta R_{X}^{b}, \delta R_{Z}, \delta M_{Y}, \delta p_{t}, \delta \Delta$, and $\delta x^{*}$ along with the corresponding natural and essential boundary conditions written in the following general form as, see e.g. Kryžanowski et al. (2009):

$x=0$ :

$$
\begin{gathered}
s_{1}^{0} \delta R_{X}^{a}(0)+s_{2}^{0} \delta u^{a}(0)=0, \\
s_{3}^{0} \delta R_{X}^{b}(0)+s_{4}^{0} \delta u^{b}(0)=0, \\
s_{5}^{0} \delta R_{Z}(0)+s_{6}^{0} \delta w(0)=0, \\
s_{7}^{0} \delta M_{Y}(0)+s_{8}^{0} \delta \varphi(0)=0,
\end{gathered}
$$

$x=L:$

$$
\begin{gathered}
s_{1}^{L} \delta R_{X}^{a}(L)+s_{2}^{L} \delta u^{a}(L)=0, \\
s_{3}^{L} \delta R_{X}^{b}(L)+s_{4}^{L} \delta u^{b}(L)=0, \\
s_{5}^{L} \delta R_{Z}(L)+s_{6}^{L} \delta w(L)=0, \\
s_{7}^{L} \delta M_{Y}(L)+s_{8}^{L} \delta \varphi(L)=0,
\end{gathered}
$$

where $s_{i} \in\{0,1\}$ are parameters that determine different combinations of boundary conditions of the two-layer composite column. The superscripts "0" and " $L "$ of $s$ identify its value at $x=0$ and $x=L$, respectively. If the linearized boundary conditions (25)-(26) are accordant with the boundary conditions (8)-(9), they are called present boundary conditions, otherwise, Girhammar boundary conditions. Since some critical buckling loads of the composite columns have been calculated from the Girhammar boundary conditions, see e.g. Girhammar and Gopu (1993), Girhammar and Pan (2007), Xu and $\mathrm{Wu}(2007 \mathrm{a})$ and, $\mathrm{Xu}$ and $\mathrm{Wu}$ (2007c), to the authors' opinion, the latter division of boundary conditions seems very reasonable in case of composite columns. On the other hand, in case of solid columns, the abovementioned 
division of the boundary conditions becomes dispensable.

\subsection{Analytical solution for critical buckling load}

Eqs. (23) and boundary conditions (25)-(26) are linear, and hence, a critical buckling load can be calculated analytically. With the systematic elimination of the primary unknowns and some regrouping the system of linearized equations (23) can be reduced to a set of three higher-order linear homogeneous ordinary differential equations with constant coefficients for $\delta w, \delta u^{a}$, and $\delta \Delta$ as

$$
\begin{aligned}
& A \delta w^{I V}+B \delta w^{\prime \prime}+C \delta \Delta^{\prime}=0, \\
& D \delta u^{a \prime \prime}+E \delta w^{\prime \prime \prime}-K \delta \Delta=0, \\
& F \delta u^{a \prime \prime}+G \delta w^{\prime \prime \prime}-F \delta \Delta^{\prime \prime}+K \delta \Delta=0,
\end{aligned}
$$

where

$$
\begin{aligned}
& A=-\frac{1}{1+\varepsilon}\left(C_{22}-\frac{C_{12}^{a} C_{21}^{a}}{C_{11}^{a}}-\frac{C_{12}^{b} C_{21}^{b}}{C_{11}^{b}}\right), \\
& B=R_{X} \\
& C=K\left(\frac{C_{21}^{a}}{C_{11}^{a}}-\frac{C_{21}^{b}}{C_{11}^{b}}\right) \\
& D=C_{11}^{a}, \\
& E=-\frac{C_{12}^{a}}{1+\varepsilon} \\
& F=C_{11}^{b}, \\
& G=-\frac{C_{12}^{b}}{1+\varepsilon}, \text { and } \\
& \delta \Delta=\delta u^{a}-\delta u^{b} .
\end{aligned}
$$

Moreover, Eqs. (27) may be replaced by three uncoupled homogeneous linear 
differential equations with constant coefficients for unknowns $\delta w, \delta \Delta$, and $\delta u^{a}$

$$
\begin{aligned}
& H \delta w^{V I}+I \delta w^{I V}+J \delta w^{\prime \prime}=0 \\
& A \delta w^{I V}+B \delta w^{\prime \prime}+C \delta \Delta^{\prime}=0 \\
& D \delta u^{a \prime \prime}+E \delta w^{\prime \prime \prime}-K \delta \Delta=0
\end{aligned}
$$

where $H, I$ and $J$ are constants defined from

$$
\begin{aligned}
& H=\frac{A D F}{C}, \\
& I=\frac{B D F-C E F+A C G-A(D+F) K}{C}, \\
& J=-\frac{B(D+F) K}{C} .
\end{aligned}
$$

The solution of $(27)$ or $(29 a)-(29 c)$ consists of nine integration constants. Consequently, due to the fact that there exist only eight basic boundary conditions, an additional boundary condition to the Eqs. (29a)-(29c) is required. For instance, it is obtained from the last equation of (29c). Thus,

$$
F \delta u^{a \prime \prime}(0)+G \delta w^{\prime \prime \prime}(0)-F \delta \Delta^{\prime \prime}(0)+K \delta \Delta(0)=0 .
$$

From (31), it is evident, that the boundary conditions in the longitudinal and transverse direction are interrelated.

The general solution of (29a) is then obtained simply by solving a corresponding characteristic polynomial, which is derived if $\delta w$ in (29a) is replaced by $e^{r x}$. Division of the derived equation by $e^{r x}$ gives (see e.g. Coddington and Levinson (1955))

$$
H r^{6}+I r^{4}+J r^{2}=0
$$

The solution of (32) is investigated parametrically for different geometric and material parameters and as a result four real $\left(\lambda_{1,2}=0, \lambda_{3}\right.$ and $\left.\lambda_{4}\right)$ and two complex roots $\left(\lambda_{6}=\beta i, \lambda_{7}=-\beta i\right)$ are obtained. According to the superpo- 
sition principle, the general solution to (29a) is therefore

$$
\delta w(x)=\mathcal{C}_{1}+\mathcal{C}_{2} x+\mathcal{C}_{3} e^{\lambda_{3}} x+\mathcal{C}_{4} e^{\lambda_{4} x}+\mathcal{C}_{5} \cos \beta x+\mathcal{C}_{6} \sin \beta x
$$

By substituting (33) into (29b), and by integrating, one can obtain a solution for $\delta \Delta$

$$
\begin{aligned}
\delta \Delta(x) & =\mathcal{C}_{2} R+\mathcal{C}_{3} \lambda_{3}\left(S \lambda_{3}^{2}+R\right) e^{x \lambda_{3}}+\mathcal{C}_{4} \lambda_{4}\left(S \lambda_{4}^{2}+R\right) e^{x \lambda_{4}}+ \\
& +\mathcal{C}_{5} \beta\left(S \beta^{2}-R\right) \sin \beta x+\mathcal{C}_{6} \beta\left(R-S \beta^{2}\right) \cos \beta x+\mathcal{C}_{7}
\end{aligned}
$$

Similarly, when $\delta w$ and $\delta \Delta$ are known functions, $\delta u^{a}$ is simply determined by the integration of the equation of $(29 \mathrm{c})$

$$
\begin{aligned}
\delta u^{a}(x) & =\mathcal{C}_{2} \frac{N}{2} x^{2}+\mathcal{C}_{3} \frac{\left(N-P \lambda_{3}^{2}\right) e^{x \lambda_{3}}}{\lambda_{3}}+\mathcal{C}_{4} \frac{\left(N-P \lambda_{4}^{2}\right) e^{x \lambda_{4}}}{\lambda_{4}}+ \\
& +\mathcal{C}_{5} \frac{\left(P \beta^{2}+N\right) \sin \beta x}{\beta}-\mathcal{C}_{6} \frac{\left(P \beta^{2}+N\right) \cos \beta x}{\beta}+\mathcal{C}_{7} \frac{K}{2 D} x^{2}+\mathcal{C}_{8} x+\mathcal{C}_{9}
\end{aligned}
$$

where

$$
\begin{aligned}
& M=-\frac{K R}{D}, \quad N=-\frac{K P}{D}, \quad O=-\frac{E}{D}, \\
& P=\frac{E-K P}{C}, \quad R=-\frac{B}{C}, \quad S=-\frac{A}{C} .
\end{aligned}
$$

When $\delta w, \delta u^{a}$, and $\delta \Delta$ are known functions of $x$, the remaining quantities of the two-layer column $\delta u^{b}, \delta \varphi, \delta R_{X}^{a}, \delta R_{X}^{b}, \delta R_{Z}, \delta M_{Y}$, and $\delta x^{*}$ and thus the general solution of the system of Eqs. (23) can easily be obtained. In order to properly consider the boundary conditions (25)-(26), it is suitable to express $\delta \varphi, \delta R_{X}^{a}, \delta R_{X}^{b}, \delta R_{Z}, \delta M_{Y}$ with (33)-(35) and their derivatives. Finally, the unknown integration constants $\mathcal{C}_{1}, \mathcal{C}_{2}, \mathcal{C}_{3}, \mathcal{C}_{4}, \mathcal{C}_{5}, \mathcal{C}_{6}, \mathcal{C}_{7}, \mathcal{C}_{8}$, and $\mathcal{C}_{9}$ are determined from the boundary conditions (25)-(26) and (31). As a result, a system of nine homogeneous linear algebraic equations for nine unknown constants is 
obtained, which, expressed in a matrix form, reads

$$
\boldsymbol{K} \boldsymbol{c}=\mathbf{0},
$$

where $\boldsymbol{K}$ and $\boldsymbol{c}$ denote a tangent matrix and a vector of unknown constants, respectively. For a non-trivial solution of (37), the determinant of the matrix should vanish, see e.g. Planinc and Saje (1999)

$$
\operatorname{det} \boldsymbol{K}=0 .
$$

The condition (38) represents a linear eigenvalue problem and its solution, i.e. the lowest eigenvalue corresponds to the smallest critical buckling load, $P_{c r}$, of the column. The explicit form of the matrix $\boldsymbol{K}$ and the analytical solution for the lowest buckling load, $P_{c r}$, can easily be determined, but they are unfortunately too cumbersome to be presented as closed-form expressions. For further details on the determination of critical points and their classification an interested reader is referred to Planinc and Saje (1999).

\section{Parametric study and discussion}

The analytical results, for critical buckling loads of geometrically perfect twolayer composite columns with interlayer slip, obtained herein with exact linear eigenvalue problem will be compared with existing buckling loads obtained by other investigators, e.g. Girhammar and Gopu (1993), Girhammar and Pan (2007), Xu and Wu (2007a) and, Xu and Wu (2007c). Thus, an influence of different boundary conditions and axial deformation on critical buckling load of two-layer composite columns will be investigated. Furthermore, a parametric analysis will also be conducted, by which a combined influence of axial 
deformation and position of supports on buckling forces of composite columns with different types of boundary conditions will be analyzed in detail.

\subsection{Influence of different boundary conditions and axial deformation on buck- ling load of a two-layer composite column}

With the intention of comparing the critical buckling loads of the present analytical model to the above-mentioned buckling models, a timber-concrete composite column is employed. This column has also been studied by other researchers, see, e.g. Adam et al. (1997), Battini et al. (2009), Girhammar and Pan (2007) and, Xu and Wu (2007a).

Consecutively, the geometrical and mechanical properties of the timber-concrete composite column are presented in Fig. 2.

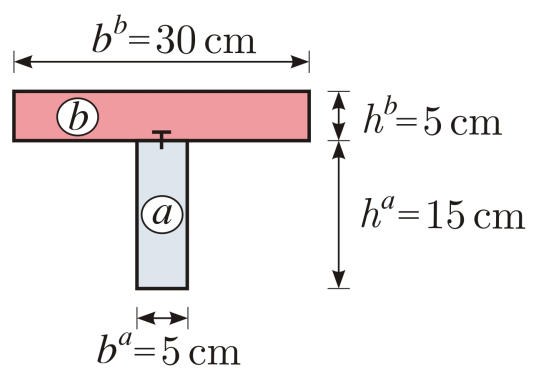

(a) Timber

(b) Concrete

$$
\frac{L}{h^{a}+h^{b}}=20
$$

$E^{a}=800 \mathrm{kN} / \mathrm{cm}^{2}$

$E^{b}=1200 \mathrm{kN} / \mathrm{cm}^{2}$

$K=5 \mathrm{kN} / \mathrm{cm}^{2}$

Figure 2. Geometrical and mechanical properties of timber-concrete column.

The critical buckling loads of timber-concrete columns with different types of boundary conditions were evaluated. Four sets of boundary conditions were considered of practical importance for columns with nonmovable supports: clamped-free column (C-F), clamped-clamped column (C-C), clamped-pinned column (C-P) and pinned-pinned column (P-P). In accordance to the bound- 
ary conditions (25)-(26), the classical boundary conditions of the two-layer Euler columns and the corresponding non-zero values of parameters $s_{i}$ and effective length coefficient, $\beta_{E}$, are summarized in Table 1.

The critical buckling loads calculated by the proposed analytical model, which incorporates the axial shortening effect on critical buckling loads, were compared to those obtained with the "second-order theory" and Girhammar boundary conditions in which the effect of axial shortening on critical loads is neglected, see, Girhammar and Gopu (1993), Girhammar and Pan (2007), Xu and $\mathrm{Wu}(2007 \mathrm{a})$ and, $\mathrm{Xu}$ and $\mathrm{Wu}(2007 \mathrm{c})$.

Therefore, critical buckling loads were computed as a function of interlayer stiffness, $K$, and compared with the results of Girhammar and Pan (2007), for two different sets of boundary conditions; for boundary conditions proposed herein, see Table 1, and for those proposed by Girhammar and Pan (2007) and stated in Table 2. In order to distinguish between these boundary conditions, an asterisk $*$ symbol is attached to the Girhammar boundary conditions in Table 2 that differ compared to those in Table 1.

Table 3 compares the critical buckling loads of Girhammar and Pan (2007), calculated for two different sets of boundary conditions, with the proposed exact critical buckling loads herein, for a two-layer pinned-pinned composite column and various values of $K$. Interestingly, it can be seen that the solution of Girhammar and Pan (2007) is in complete agreement with the present results if in the present analysis the Girhammar boundary conditions given in Table 2 are employed and if axial shortening is neglected. On the other hand, the solution of Girhammar and Pan (2007) for boundary conditions given in Table 2 differs compared to the exact results. The discrepancy is the 
Table 1

Present two-layer column boundary conditions, effective length coefficients $\beta_{E}$ and buckled shapes of Euler columns.

\begin{tabular}{|c|c|c|c|c|}
\hline Classical cases & $\mathrm{C}-\mathrm{F}$ & $\mathrm{C}-\mathrm{C}$ & C-P & $\mathrm{P}-\mathrm{P}$ \\
\hline $\begin{array}{c}\text { Non-zero values } \\
s_{i}\end{array}$ & $\begin{array}{l}s_{2}^{0}=s_{4}^{0}=1 \\
s_{6}^{0}=s_{8}^{0}=1 \\
s_{1}^{L}=s_{3}^{L}=1 \\
s_{5}^{L}=s_{7}^{L}=1\end{array}$ & $\begin{array}{l}s_{2}^{0}=s_{4}^{0}=1 \\
s_{6}^{0}=s_{8}^{0}=1 \\
s_{1}^{L}=s_{3}^{L}=1 \\
s_{6}^{L}=s_{8}^{L}=1\end{array}$ & $\begin{array}{c}s_{2}^{0}=s_{4}^{0}=1 \\
s_{6}^{0}=s_{8}^{0}=1 \\
s_{1}^{L}=s_{3}^{L}=1 \\
s_{6}^{L}=s_{7}^{L}=1\end{array}$ & $\begin{array}{l}s_{2}^{0}=s_{4}^{0}=1 \\
s_{6}^{0}=s_{7}^{0}=1 \\
s_{1}^{L}=s_{3}^{L}=1 \\
s_{6}^{L}=s_{7}^{L}=1\end{array}$ \\
\hline $\begin{array}{c}\text { Effective length } \\
\text { coefficient }\end{array}$ & $\beta_{E}=2$ & $\beta_{E}=0.5$ & $\beta_{E}=0.699 \ldots$ & $\beta_{E}=1$ \\
\hline Buckled shape & $\underset{\text { गIIII, }}{\stackrel{4}{x} z} z$ & IIIA: & & \\
\hline
\end{tabular}

$\mathrm{C}=$ clamped $($ fixed $) ; \mathrm{F}=$ free $; \mathrm{P}=$ pinned

largest for values of inter-layer slip modulus, $K$, which usually exists in actual practice. Note also that in the limiting case when there is absolutely stiff connection $(\Delta=0 ; K \rightarrow \infty)$ or there exists no connection between the layers ( $\left.\Delta=\Delta_{\text {max }} \neq 0 ; K \rightarrow 0\right)$, the solutions where the influence of axial shortening on buckling loads is neglected agree completely. This is due to the fact, that in the limiting case, the boundary conditions of the composite columns in longitudinal and transverse directions become mutually independent and are the same as for solid columns. From the results, it can also be proved that the critical buckling loads increase with the inclusion of axial deformability, 
Table 2

Two-layer column boundary conditions and effective length coefficients $\beta_{E}$ proposed by Girhammar and Pan (2007). In fact, these are our boundary conditions that gave the same solution as in Girhammar and Pan (2007). The boundary conditions that are different compared to the present boundary conditions are written as bold-faced type and marked by an asterisk $*$ symbol.

\begin{tabular}{|c||c|c|c|c|}
\hline \hline Classical cases & C-F & C-C* & C-P & P-P* \\
\hline \hline \multirow{4}{*}{$\begin{array}{c}\text { Non-zero values } \\
s_{i}\end{array}$} & $s_{2}^{0}=s_{4}^{0}=1$ & $s_{2}^{0}=s_{4}^{0}=1$ & $s_{2}^{0}=s_{4}^{0}=1$ & $s_{2}^{0}=\boldsymbol{s}_{\mathbf{3}}^{\mathbf{0}}=1$ \\
& $s_{6}^{0}=s_{8}^{0}=1$ & $s_{6}^{0}=s_{8}^{0}=1$ & $s_{6}^{0}=s_{8}^{0}=1$ & $s_{6}^{0}=s_{7}^{0}=1$ \\
& $s_{1}^{L}=s_{3}^{L}=1$ & $\boldsymbol{s}_{\mathbf{2}}^{\boldsymbol{L}}=\boldsymbol{s}_{\mathbf{4}}^{\mathbf{L}}=\mathbf{1}$ & $s_{1}^{L}=s_{3}^{L}=1$ & $s_{1}^{L}=s_{3}^{L}=1$ \\
& $s_{5}^{L}=s_{7}^{L}=1$ & $s_{6}^{L}=s_{8}^{L}=1$ & $s_{6}^{L}=s_{7}^{L}=1$ & $s_{6}^{L}=s_{7}^{L}=1$ \\
\hline \multirow{2}{*}{$\begin{array}{c}\text { Effective length } \\
\text { coefficient }\end{array}$} & $\beta_{E}=2$ & $\beta_{E}=0.5$ & $\beta_{E}=0.699 \ldots$ & $\beta_{E}=1$ \\
\hline \hline
\end{tabular}

$\mathrm{C}=$ clamped (fixed); $\mathrm{F}=$ free $\mathrm{P}=$ pinned

as expected.

In the sequel, an influence of boundary conditions in axial deformation on the critical buckling loads of composite columns will be studied for other types of boundary conditions presented in Table 1 and 2 .

The effect of axial deformability may be analyzed by defining a relative error which was here defined as

$$
\varepsilon_{r}[\%]=\frac{P_{\mathrm{cr}}\left(\varepsilon_{\mathrm{cr}} \neq 0\right)-P_{\mathrm{cr}}\left(\varepsilon_{\mathrm{cr}}=0\right)}{P_{\mathrm{cr}}\left(\varepsilon_{\mathrm{cr}} \neq 0\right)} \times 100
$$

where $P_{\mathrm{cr}}\left(\varepsilon_{\mathrm{cr}} \neq 0\right)$ and $P_{\mathrm{cr}}\left(\varepsilon_{\mathrm{cr}}=0\right)$ represent critical forces obtained by the proposed analytical procedure where axial deformability is and is not taken 
Table 3

Comparison of the proposed critical buckling loads of P-P two-layer composite column with those of Girhammar and Pan (2007) for different boundary conditions and various $K \mathrm{~s}$.

\begin{tabular}{|c|c|c|c|c|}
\hline & & $P_{\mathrm{cr}}[\mathrm{kN}]$ & & \\
\hline$K\left[\mathrm{kN} / \mathrm{cm}^{2}\right]$ & $\begin{array}{c}\text { Girhammar \& Pan } \\
\qquad(2007)^{\text {a }}\end{array}$ & $\begin{array}{c}\text { present } \\
\varepsilon_{\text {cr }}=0 \text { \%↔ }\end{array}$ & $\begin{array}{l}\text { present } \\
\varepsilon_{\mathrm{cr}}=0\end{array}$ & $\begin{array}{c}\text { present } \\
\varepsilon_{\mathrm{cr}}=\frac{-P_{\mathrm{cr}}}{C_{11}^{a}+C_{11}^{b}}\end{array}$ \\
\hline $10^{-10}$ & 92.5275413 & 92.5275413 & 92.5275413 & 92.5632411 \\
\hline $10^{-5}$ & 92.5285413 & 92.5305413 & 92.5305412 & 92.5662433 \\
\hline $10^{-3}$ & 92.6275052 & 92.6275052 & 92.8268019 & 92.8627331 \\
\hline $10^{-2}$ & 93.5239516 & 93.5239516 & 95.4553844 & 95.4933802 \\
\hline $10^{-1}$ & 102.1798151 & 102.1798151 & 116.7264005 & 116.7832269 \\
\hline 1 & 166.0432717 & 166.0432717 & 197.0811991 & 197.2433030 \\
\hline $10^{1}$ & 309.7993001 & 309.7993001 & 317.4300916 & 317.8510469 \\
\hline $10^{2}$ & 362.6130603 & 362.6130603 & 362.9967378 & 363.5474325 \\
\hline $10^{3}$ & 369.3417768 & 369.3417768 & 369.3546149 & 369.9247997 \\
\hline $10^{5}$ & 370.1024600 & 370.1024600 & 370.1024730 & 370.6749727 \\
\hline $10^{10}$ & 370.1101649 & 370.1101649 & 370.1101649 & 370.6826885 \\
\hline
\end{tabular}

* Girhammar and Pan (2007) solution for Girhammar boundary conditions given in Table 2

24. present solution for Girhammar boundary conditions given in Table 2

into account, respectively. Thus, Fig. 3 presents the variation of $\varepsilon_{r}$ for various column end conditions (see Table 1 ) and various values of $K$. The results show that axial deformability of columns increases the buckling load. The effect of axial deformability on critical buckling loads increases with respect to increasing values of $K$. The increase is more pronounced for C-C and C-P columns when compared to the columns with other boundary conditions. For 


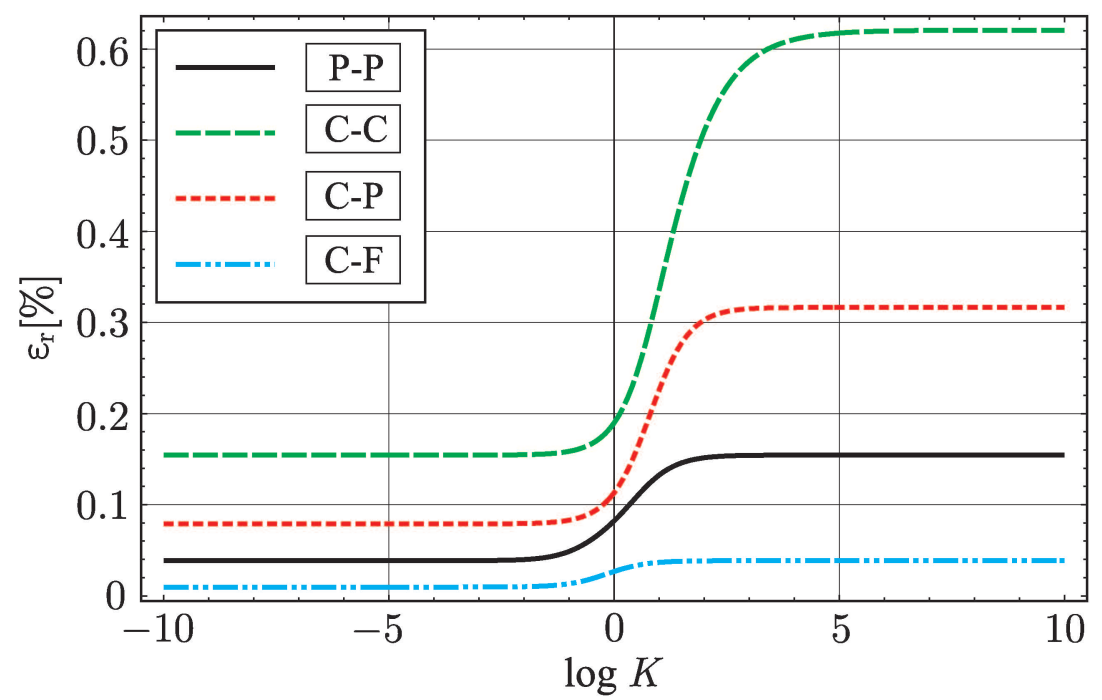

Figure 3 . The effect of axial deformability on critical buckling loads of geometrically perfect two-layer composite column for various column end conditions and different $K \mathrm{~s} ;$ where $K\left[\mathrm{kN} / \mathrm{m}^{2}\right]$.

example, for practical value of $K=10 \mathrm{kN} / \mathrm{cm}^{2}(\log K=1), \varepsilon_{r}[\mathrm{C}-\mathrm{C}]=0.335$; $\varepsilon_{r}[\mathrm{C}-\mathrm{P}]=0.226 ; \varepsilon_{r}[\mathrm{P}-\mathrm{P}]=0.132 ; \varepsilon_{r}[\mathrm{C}-\mathrm{F}]=0.037$; while, in the limiting case, when there is an absolutely stiff connection $(\Delta=0 ; K \rightarrow \infty), \varepsilon_{r}[\mathrm{C}-\mathrm{C}]=0.621$; $\varepsilon_{r}[\mathrm{C}-\mathrm{P}]=0.317 ; \varepsilon_{r}[\mathrm{P}-\mathrm{P}]=0.155 ; \varepsilon_{r}[\mathrm{C}-\mathrm{F}]=0.039$. Evidently, the effect of axial deformability on critical buckling loads is in this case negligible.

Similarly, the effect of column boundary conditions on critical buckling loads may be analyzed by defining a relative error which was here defined as

$$
\varepsilon_{r}[\%]=\frac{P_{\mathrm{cr}}\left(\varepsilon_{\mathrm{cr}}=0\right)-P_{\mathrm{cr}}^{\mathrm{G}}}{P_{\mathrm{cr}}\left(\varepsilon_{\mathrm{cr}}=0\right)} \times 100
$$

in which $P_{\mathrm{cr}}^{\mathrm{G}}$ denotes a critical force of Girhammar and Pan (2007) obtained by column boundary conditions given in Table 2 .

It is interesting to note that the discrepancy between the exact buckling loads and buckling loads of Girhammar and Pan (2007) obtained by the secondorder theory is interlayer-slip modulus dependent and is present only in P-P 


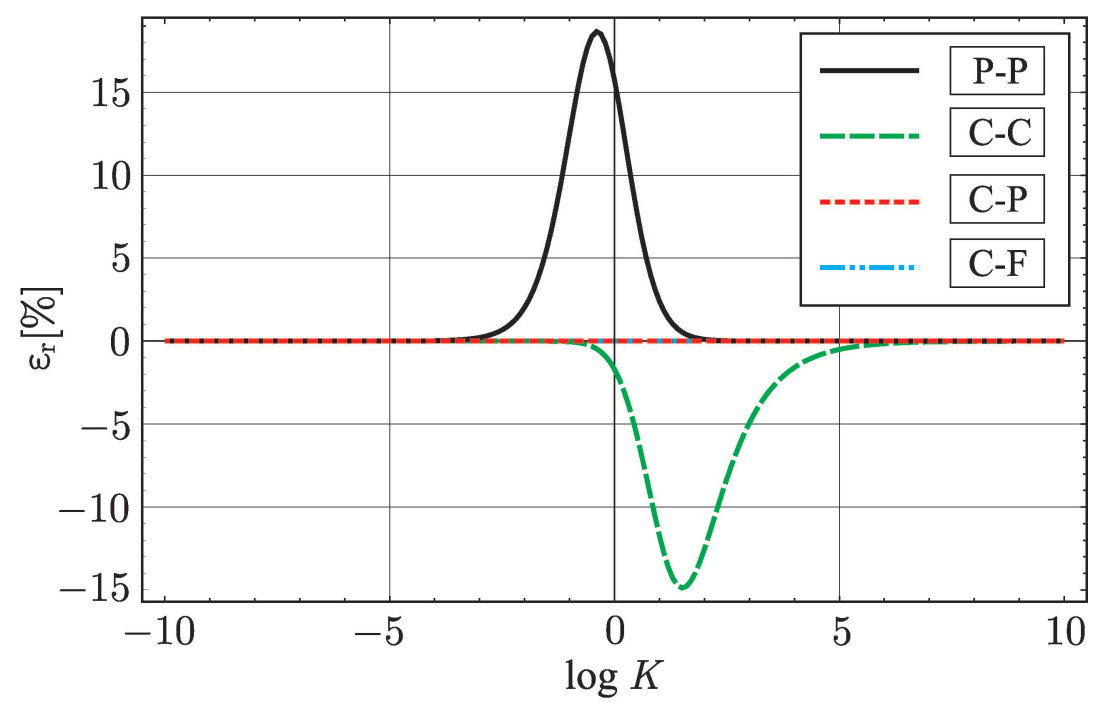

Figure 4. The effect of column end conditions on critical buckling loads of geometrically perfect two-layer composite column for various values of $K$; where $K\left[\mathrm{kN} / \mathrm{m}^{2}\right]$. and $\mathrm{C}-\mathrm{C}$ column case as expected. Of the values shown in Fig. 4, the maximum discrepancy is for the P-P column and is about $18.65 \%$. On the other hand, critical force $P_{\mathrm{cr}}^{\mathrm{G}}$ is in $\mathrm{C}-\mathrm{C}$ column case as much as approximately $14.88 \%$ higher than the exact ones. Apparently, in this case, the buckling load calculated by Girhammar and Pan (2007) is rather conservative. It is clear that different end conditions have a considerable influence on critical buckling loads of two-layer composite columns, especially for practical values of $K$.

4.2 Parametric study of the combined affect of axial deformability and position of end supports on critical buckling loads of two-layer composite column

This section presents a parametric study that was conducted in order to illustrate how the critical buckling loads of two-layer composite columns are affected by axial deformability and different arrangement of end supports. In particular, it was examined how these effects are influenced by the inter-layer 
slip modulus, $K$, and column slenderness, $\lambda$.

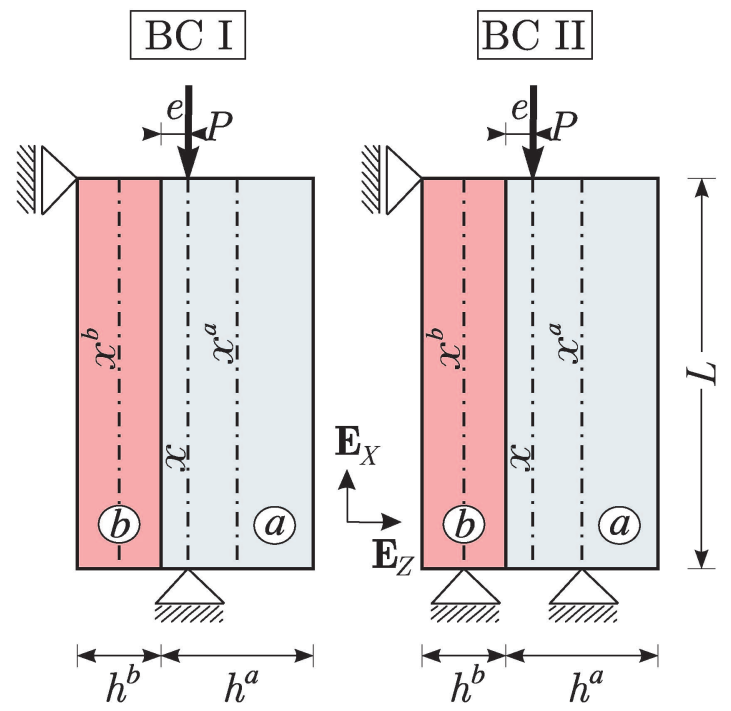

Figure 5. Different arrangements of column end supports.

For this purpose critical buckling loads of two-layer composite column (see Fig. 2) were calculated for different arrangement of column end supports (see Fig. 5), different values of parameters $K$ and different boundary conditions. Of the four boundary conditions studied, the results are different only for P-P column case. The results are plotted in Figs. 6 and 7.

Fig. 6 shows the variation of the buckling load, $P_{\text {cr }}$, with respect to interlayer modulus, $K$, for two different arrangements of P-P column end supports, i.e. BC I and BC II, respectively. Obviously, the effect of the position of end supports becomes considerably important with increasing values of $K$. For the limiting case, where there is an absolutely stiff connection $(\Delta=0 ; K \rightarrow \infty)$, $P_{\mathrm{cr}}^{\mathrm{BC} I \mathrm{II}}$ is as much as two times larger than $P_{\mathrm{cr}}^{\mathrm{BC}}$.

Similarly, Fig. 7 shows the variation of the effect of axial deformability of the two-layer composite column on its critical buckling forces. This effect is represented with $\varepsilon_{r}$ defined by Eq. (39). 


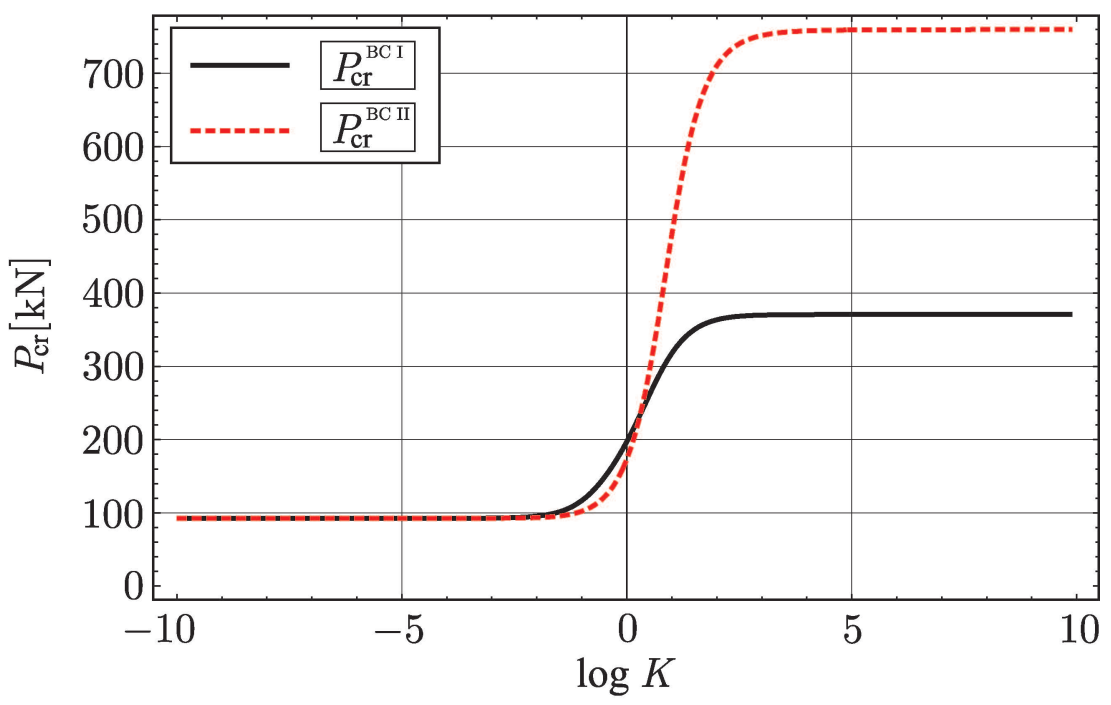

Figure 6. Critical buckling load, $P_{c r}$, for different $K \mathrm{~s}$, and different arrangements of P-P column end supports; where $K\left[\mathrm{kN} / \mathrm{m}^{2}\right]$.

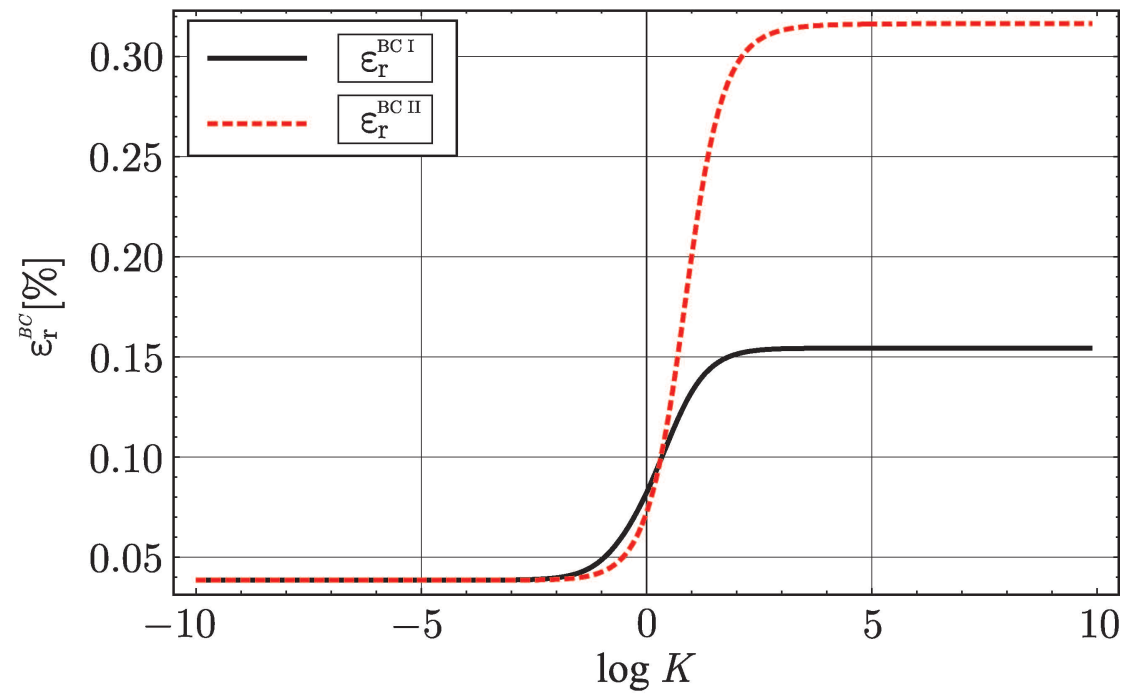

Figure 7. The effect of axial shortening on $P_{c r}$ for different $K \mathrm{~s}$, and different arrangements of P-P column end supports; where $K\left[\mathrm{kN} / \mathrm{m}^{2}\right]$.

From the results, the form of variation of the effect of axial shortening is identical with the one presented in Fig. 7. Consequently, the effect of axial deformability on buckling loads (on the increase of buckling load) is more significant in the BC II case. Nevertheless, in both cases, the effect of axial deformability is negligible and can be neglected. 
Additionally, the effect of axial deformability on the critical buckling load, $P_{c r}$, of the geometrically perfect two-layer composite columns with partial interlayer connection between the layers were analyzed for various inter-layer slip moduli $K$ and for different column slenderness $\lambda$ which is defined as

$$
\lambda=\frac{\beta_{E} L \sqrt{A^{a}+A^{b}}}{\sqrt{I^{a}+I^{b}}},
$$

where $\beta_{E}$ represents the effective length coefficient of Euler columns with stiff connection between the layers. Effective length coefficients, $\beta_{E}$, are given in Table 1 for different types of end conditions along with schematic illustrations of the buckling modes. Variation in column slenderness was achieved by considering a range of column lengths.

The results show that allowance for axial deformability increases the critical buckling loads when the columns are short or stocky (i.e. for large values of column slenderness, $\lambda$ ) and for higher values of the inter-layer slip modulus, $K$, in all cases of boundary conditions. From Fig. 8, it can be observed, that

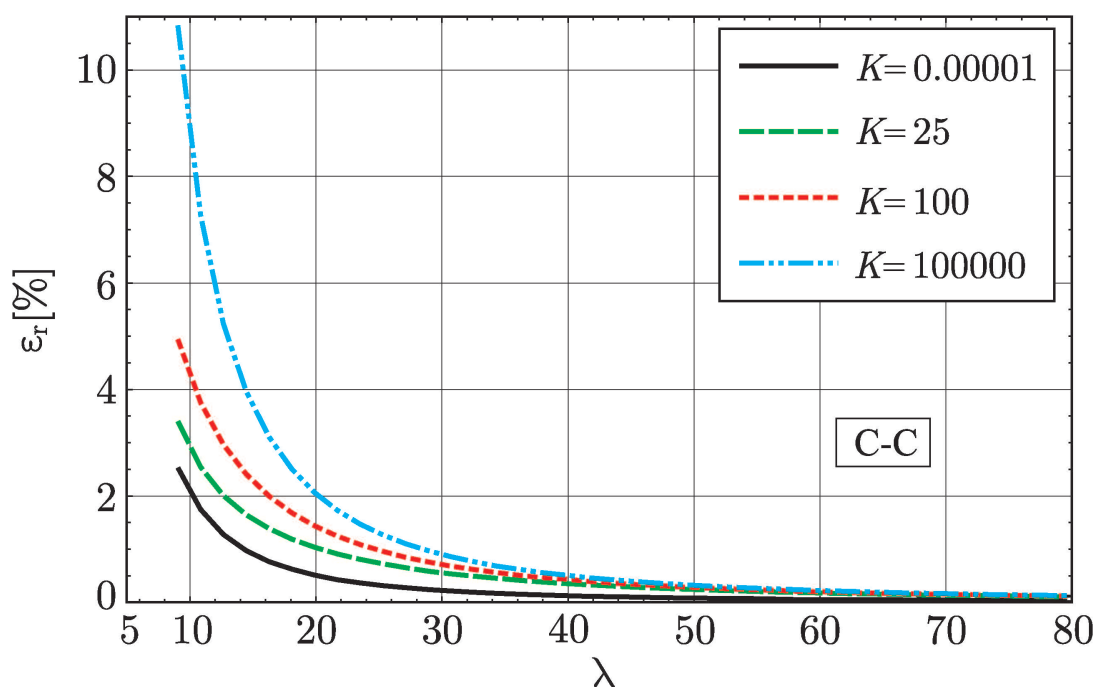

Figure 8. The effect of axial deformability on $P_{c r}$ for different column slenderness, $\lambda$, and various $K \mathrm{~s}$ for the C-C column case; where $K\left[\mathrm{kN} / \mathrm{m}^{2}\right]$. 
the effect of axial deformability in the C-C column case becomes important with decreasing values of $\lambda$ (for $\lambda \leq 20$ ), raising the critical load when $\lambda=10$ by up to $10.84 \%$ for $K=100000 \mathrm{kN} / \mathrm{cm}^{2}$ and, by contrast, up to $2.53 \%$ for $K=0.00001 \mathrm{kN} / \mathrm{cm}^{2}$. However, the curves for the different interlayer modulus, $K$, with column slenderness, $\lambda$, higher than 50 coincide as the effect due to axial deformability is almost negligible when the columns are very slender.

\section{Conclusions}

This paper presents a detailed analysis of the influence of different boundary conditions and axial deformation on the critical buckling loads of the geometrically perfect two-layer composite columns with inter-layer slip between the layers. Based on the theoretical and numerical results the following important conclusions can be drawn:

(1) It was shown, that for composite columns with interlayer slip, the boundary conditions in the longitudinal and transverse directions are interrelated. Namely, that is different than in the solid column case, where the boundary conditions in both directions are unrelated.

(2) A significant discrepancy between the critical buckling loads obtained by different longitudinal boundary conditions were obtained. A difference can be up to $20 \%$ for the P-P column and $14 \%$ in the C-C column case. Besides, this discrepancy is proved to be interlayer-slip modulus and boundary conditions dependent.

(3) As anticipated, the effect of axial deformability on the buckling load of composite columns is significant for short or stocky columns. The allowance for axial deformability increases the critical buckling of these 
columns. This is especially true for higher values of interlayer-slip modulus. On the other hand, the effect of axial deformability is almost negligible when the columns are very slender.

(4) The position of the column supports proved to have an important influence on critical buckling loads.

\section{Acknowledgement}

The authors acknowledge the financial support from the state budget by the Slovenian Research Agency (project No. Z2-2031). In addition, the authors would also like to thank Mrs. Romana Hudin for a detailed language review of this paper.

\section{References}

Adam, C., Heuer, R., Jeschko, A., 1997. Flexural vibrations of elastic composite beams with interlayer slip. Acta Mechanica 125 17-30.

Battini, J.M., Nguyen, Q.H., Hjiaj, M., 2009. Non-linear finite element analysis of composite beams with interlayer slips. Computers and Structures $87904-$ 912.

Chen, W.Q., Wu, Y.F., Xu, R.Q, 2007. State space formulation for composite beam-columns with partial interaction. Composites Science and Technology $672500-2512$.

Čas, B., Saje, M., Planinc, I., 2004. Non-linear finite element analysis of composite planar frames with an interlayer slip. Computers and Structures 82 1901-1912.

Čas, B., Bratina, S., Saje, M., Planinc, I., 2004. Non-linear analysis of composite steel-concrete beams with incomplete interaction. Steel and Composite 
Structures 4(6) 489-507.

Čas, B., Saje, M., Planinc, I., 2007. Buckling of layered wood columns. Advances in Engineering Software 38 586-597.

Coddington, E.A., Levinson, N., 1955. Theory of ordinary differential equations. McGraw-Hill, New York, Toronto, London.

Dall'Asta, A., Zona, A., 2004. Comparison and validation of displacement and mixed elements for the non-linear analysis of continuous composite beams. Computers and Structures 82(23-26) 2117-2130.

Flajs, R., Saje, M., Zakrajšek, E., 2003. On the existence and uniqueness of the generalized solution of the Reissner's elastica. Mathematics and Mechanics of Solids 8 3-19.

Foraboschi, P., 2009. Analytical solution of two-layer beam taking into account nonlinear interlayer slip. Journal of Engineering Mechanics 135(10) 11291146.

Girhammar, U.A., Gopu, V.K.A., 1993. Composite beam-columns with interlayer slip-exact analysis. Journal of Structural Engineering 119(4) 12651282.

Girhammar, U.A., Pan, D.H., 2007. Exact static analysis of partially composite beams and beam-columns. Int. J. Mech. Sci. 49 239-255.

Heuer, R., Adam, C., 2000. Piezoelectric vibrations of composite beams with interlayer slip. Acta Mechanica 140 247-263.

Heuer, R., 2004. Equivalence of the analyses of sandwich beams with or without interlayer slip. Mechanics of Advanced Materials and Structures 11 425432.

Hartmann, F., 1985. The Mathematical Foundation of Structural Mechanics. Springer-Verlag Berlin and Heidelberg GmbH \& Co.K.

Keller, H.B., 1970. Nonlinear bifurcation. Journal of Differential Equations 7 
$417-434$.

Kryžanowski, A., Saje, M., Planinc, I., Zupan, D., 2008. Analytical solution for buckling of asymmetrically delaminated Reissner's elastic columns including transverse shear. Int. J. Solids. Struct. 45 1051-1070.

Kryžanowski, A., Schnabl, S., Turk, G., Planinc, I., 2009. Exact slip-buckling analysis of two-layer composite columns. Int. J. Solids. Struct. 46 2929-2938.

Challamel, N., 2009. On lateral-torsional vibrations of elastic composite beams with interlayer slip. Journal of Sound and Vibration 325(4-5) 1012-1022.

Planinc, I., Saje, M., 1999. A quadratically convergent algorithm for the computation of stability points: The application of the determinant of the tangent stiffness matrix. Computer Methods in Applied Mechanics and Engineering 169 89-105.

Ranzi, G., Bradford, M.A., 2007a. Direct stiffness analysis of a composite beam-column element with partial interaction Computers \& Structures $85(15-16)$ 1206-1214.

Ranzi, G., Zona, A., 2007b. A steel-concrete composite beam model with partial interaction including the shear deformability of the steel component. Engineering Structures 29(11) 3026-3041.

Ranzi, G., 2008. Locking problems in the partial interaction analysis of multilayered composite beams. Engineering Structures 30(10) 2900-2911.

Rassam, H.Y, Goodman, J.R., 1970. Buckling behaviour of layered wood columns. Wood Science 2(4) 238-246.

Reissner, E., 1972. On one-dimensional finite-strain beam theory: The plane problem. Journal of Applied Mechanics and Physics (ZAMP) 23 795-804.

Schnabl, S., Planinc, I., Saje, M., Čas, B. and Turk, G., 2006. An analytical model of layered continuous beams with partial interaction. Structural Engineering and Mechanics 22 (3) 263-278. 
Schnabl, S., Saje, M., Turk, G. and Planinc, I., 2007a. Locking-free two-layer Timoshenko beam element with interlayer slip. Finite Elements in Analysis and Design 43 705-714.

Schnabl, S., Saje, M., Turk, G. and Planinc, I., 2007b. Analytical solution of two-layer beam taking into account interlayer slip and shear deformation. Journal of Structural Engineering ASCE 133(6) 886-894.

Silva, A.R., Sousa, J.B.M., 2009. A family of interface elements for the analysis of composite beams with interlayer slip. Finite Elements in Analysis and Design 45(5) 305-314.

Vratanar, B., Saje, M., 1999. A consistent equilibrium in a cross-section of an elastic-plastic beam. Int. J. Solids. Struct. 36 311-337.

Xu, R., Wu, Y., 2007. Static, dynamic, and buckling analysis of partial interaction composite members using Timoshenko's beam theory. Int. J. Mech. Sci. 49(10) 1139-1155.

Xu, R., Wu, Y., 2007. Two-dimensional analytical solutions of simply supported composite beams with interlayer slips. Int. J. Solids. Struct. 44 165175 .

Xu, R., Wu, Y., 2007. Free vibrations of the partial-interaction composite members with axial force. Journal of Sound and Vibration 299 1074-1093.

Xu, R., Wu, Y., 2008. Free vibration and buckling of composite beams with interlayer slip by two-dimensional theory. Journal of Sound and Vibration 313 875-890. 